\title{
A Review on Impacts of Power Quality, Control and Optimization Strategies of Integration of Renewable Energy Based Microgrid Operation
}

\author{
W. J. Praiselin \\ VIT University/School of Electrical Engineering, Vellore, 632014, India \\ E-mail: praiselin.wj2015@vit.ac.in \\ J. Belwin Edward \\ VIT University/School of Electrical Engineering, Vellore, 632014, India \\ E-mail: jbelwinedward@vit.ac.in
}

Received: 29 March 2017; Accepted: 05 June 2017; Published: 08 March 2018

\begin{abstract}
Due to the global demand for energy saving and reduction of greenhouse gas emissions, utilization of renewable energy sources have increased in electricity networks. The negative aspects of this technology are very complex and not well known which affect reliability and robustness of the grids. Microgrids based on renewable energy sources have gained significant popularity, due to the major benefits it has to offer for solving the increasing energy demand. Harmonic distortion in microgrids caused by the non-linear loads is an essential topic of study necessary for the better understanding of power quality impacts in microgrids. The various control techniques utilized to curtail the power quality impacts on micro grids are reviewed in this paper. Also, Optimization based control techniques utilized for power quality improvement in microgrids is discussed in this review.
\end{abstract}

Index Terms-Microgrids, power quality, harmonic distortion, droop control, renewable energy.

\section{INTRODUCTION}

Rapid increase in energy demand of the developing nations has put pressure on the availability and cost of all natural resources. In many growing countries, including India, the grid control creates an additional challenge. Due to the highly complicated system of our modern electric grid, the integration of renewable energy sources possess various problems due to the intermittent nature of the source, unpredictable power generation and transmission from rural areas through the weak network. Wind energy is a pioneer among all other renewable energy sources, which has the sun a huge growth and development recently. In all over the world above 28,000 wind turbines are generating profitable. Grid connected renewable energy sources are sensitive to the power quality issues which includes the voltage sag, voltage swell, harmonic distortion, transients, frequency variations, multiple notches and voltage flicker [1]. Due to the power quality issues, the grid will experience loss of generation which may cause grid instability and insecurity [2]. The integration of renewable energy sources and distributed generation into conventional power systems causes power quality disturbances in the grid. Therefore, power quality monitoring is an essential concern to protect the electrical and electronics equipment [3]. Constantly testing the reliable, steady, effective and economic operation of the grid is essential to maintain the power quality [4]. Among the major issue of power quality issues, harmonic distortion is caused by non-linear loads connected to the electrical power system possess a major challenge [5]. The harmonic current flowing across the microgrid will cause power loss in transmission lines and reduces load capacity.

The microgrid is a cluster of loads and micro sources that act as a single controllable system which injects electrical power to its localized station and regional grid. Over the past 30 years, microgrids played a major role in the world's clean energy conversion and the culmination of the energy improvements. Microgrid includes most of clean energy's valuable technologies like renewable, combined heat and power, systems management, energy storage, energy efficiency and demand response. They can be operated either in the normally interconnected mode or islanded mode [59]. The most familiar voltage quality problems in a microgrid and utility system are the unbalanced grid voltages and the utility voltage sags on the whole system performance. In the modern microgrid, power electronic devices are used for monitoring and compensating the improvement of power quality events $[6,7]$. Fig.1 shows a basic arrangement of the microgrid. Microgrid loads are generally classified into fixed and flexible loads. Under normal operating conditions, fixed load should be satisfied whereas flexible loads are controlled by the signals. It could be curtailable loads in response to islanding requirements [8]. In the grid connected mode, the microgrid injects a power into the utility grid depending on the generation and load demand. 
In islanded microgrid, voltage controller is used for lack of utility grid which can work as one grid forming unit. When MG operates an islanded mode, all converter control and local loads manage power with high efficiency. During grid faults islanded system provides uninterruptible power supplies for local loads.

Droop based control methods are widely applied in microgrids which can operate without the need for communication and to avoid a critical information for accuracy basis $[9,10]$. The contribution of droop control technique is more efficient to boost the real and reactive power control in grid connected and islanded operation [66].

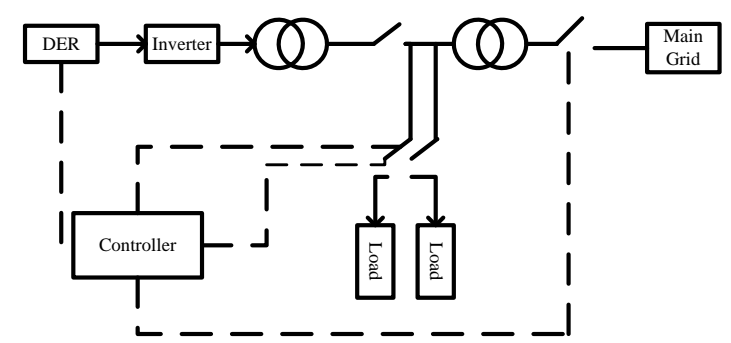

Fig.1. A typical microgrid [8].

In this paper, the feature to evaluate the challenges of the microgrid is discussed, and power quality issues due to harmonic distortion in microgrids are presented. In Section 2, indices of various power quality problems in grid side are illustrated. Section 3 discusses the harmonic detection schemes in various discrete fourier transforms. In Section 4 discusses various droop control techniques in the microgrid, also its merits and demerits are presented in this part. Section 5 indices an optimization technique in the microgrid. In Section 6 and 7 discusses the application of renewable energy sources and discussion \& future visions are presented in this part. Moreover, a detailed study of various classification of microgrid has been illustrated in Table 1 .

\section{POWER QuALITY ISSUES}

Disturbances of power frequency, faulty connections, harmonic distortion, the variation of power factor, electromagnetic interferences are present in power quality problems (70\% to $80 \%$ ) either in the supply of source side or load side [11,12]. To alleviate PQ problem consumers are equipped with various backup instruments distant from the grid supply. This chapter describes the power quality disturbances, also Fig. 2 shows that the classification of grid side power quality issues.

Renewable energy source like hydropower cause a smaller amount of power quality issues compared to other sources like wind and solar energy systems. Power quality issues related to the distributed generation sources (DG's) have been illustrated in Table.2 $[11,73]$.

\section{A. Voltage variations}

In distribution network, operators have major challenges to compensate the voltage variation due to variable wind generation and dynamic voltage stability. Voltage variations generally occur from changes in velocity of the wind and generator torque. The deviation of voltage is also affected the real and reactive power of the system [13]. The voltage variation is usually divided into four types which include voltage sag, voltage swell, short interruption and long duration voltage variation.

\section{B. Voltage sag}

Voltage sag is an incidence where the RMS (Root Mean Square) voltage less than the nominal voltage at the power frequency. Sag is caused by sudden changes in loads such as faults, motor starting and sudden increases in source impedance, usually caused by a connection failure [14]. Various type of faults in three- phase grid such as $1 \varphi$ to neutral, phase to phase, $2 \varphi$ to neutral, $3 \varphi$ faults it leads to different voltage sag. Fault location, equivalent network model, properties of the transformer interface, and fault type are the causes of voltage sag at the wind turbine units [15]. IEEE- 519 represents the standards of power quality based on the factors such as distributed generation (DG) costs and voltage sag [60].

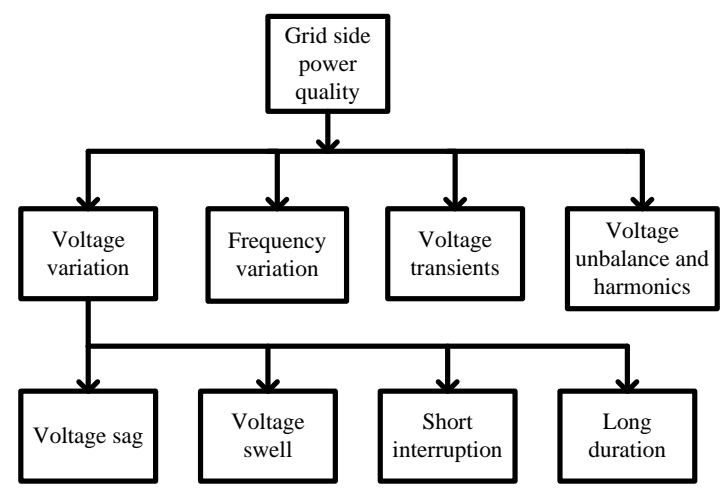

Fig.2. Classification of power quality.

\section{Voltage swell}

Voltage swell is a raise in voltage greater than the time range (0.5-30). The main causes of voltage swells are a sudden reduction in load on a circuit with the damaged voltage regulator [16]. In literature [17], voltage swell generates unexpected harmonics of current to the grid by induction melting furnace (IMF) system. Because the voltage swells mainly occur on the faults condition inside or outside of the small steel metal.

\section{Short Interruptions}

Short interruptions are the major power quality concern for loads that are fed from the grid. Generally, interruption is defined as the decrease in the voltage supply to less than $10 \%$ of nominal for up to one- minute duration. It is typically caused by the reclosing of a circuit breaker, switching to a healthy supply, automatic transfer switches in industrial networks. Short interruptions occur at the point of common coupling (PCC) which is connected to consumers and utility units. Also, based on the load with respect to sag and swells containing its asymmetrical phase angle and magnitude [18].

I.J. Intelligent Systems and Applications, 2018, 3, 67-81 


\section{E. Long duration voltage variation}

The deviation of RMS variation in the voltage for longer than 1 minute at power frequencies. Long duration variation consists of under voltages and over voltages and sustained interruptions. Less than 90\% decrease in RMS voltage at power frequency is defined as under voltage and increase in RMS voltage more than $110 \%$ at the power frequency for longer than a minute can be defined as over voltage. These conditions occur due to load variations in the system, switching of large capacitor banks or due to incorrect tap setting of transformers.
These occurrences reduce the lifetime of the power system equipment. When zero voltage is sustained for longer than a minute, it can be studied as a sustained interruption and necessary action can be appropriated [19, 20]. When the fluctuation occurs in the generation of power from the renewable energy resources because of the changes in environmental constraints [61].The frequency range of voltage fluctuation in the wind turbine is $10-35 \mathrm{~Hz}$ and International Electro-technical Commission IEC-61400 standards indicate the measuring value of flicker meter exactly [1].

Table 1. Classification of Microgrid

\begin{tabular}{|c|c|c|c|c|c|c|c|}
\hline & Classification & $\begin{array}{c}\text { Integrated } \\
\text { level }\end{array}$ & $\begin{array}{c}\text { Impact on } \\
\text { utilities }\end{array}$ & $\begin{array}{c}\text { Area of } \\
\text { applications }\end{array}$ & $\begin{array}{c}\text { Mode of } \\
\text { operation }\end{array}$ & $\begin{array}{c}\text { Quality of } \\
\text { power }\end{array}$ & Observations \\
\hline 1. & $\begin{array}{l}\text { Utility } \\
\text { microgrid }\end{array}$ & High & $\begin{array}{c}\text { Huge } \\
\text { amount of } \\
\text { impact on } \\
\text { utilities }\end{array}$ & $\begin{array}{c}\text { Quickly } \\
\text { developing } \\
\text { countries for } \\
\text { renewable } \\
\text { energy like } \\
\text { China, } \\
\text { Europe, and } \\
\text { Japan. }\end{array}$ & $\begin{array}{c}\text { Grid } \\
\text { connected } \\
\text { mode }\end{array}$ & Average & $\begin{array}{c}\text { High power } \\
\text { quality. } \\
\text { High reliability. } \\
\text { Robust. } \\
\text { Stability could } \\
\text { be controlled. }\end{array}$ \\
\hline 2. & $\begin{array}{l}\text { Industrial } \\
\text { microgrid }\end{array}$ & Middle & $\begin{array}{c}\text { Small } \\
\text { utilities } \\
\text { impact }\end{array}$ & $\begin{array}{c}\text { North } \\
\text { America, } \\
\text { particularly } \\
\text { for industrial } \\
\text { and } \\
\text { institution } \\
\text { application. }\end{array}$ & $\begin{array}{l}\text { Intentional } \\
\text { islanded } \\
\text { mode or } \\
\text { unintention } \\
\text { al islanded } \\
\text { mode }\end{array}$ & High & $\begin{array}{l}\text { High efficiency. } \\
\text { Pollution could } \\
\text { be reduced. } \\
\text { High power } \\
\text { quality. } \\
\text { Reliability for } \\
\text { sensitive loads. }\end{array}$ \\
\hline 3. & $\begin{array}{l}\text { Remote } \\
\text { microgrid }\end{array}$ & Low & No impacts & $\begin{array}{l}\text { Islands, } \\
\text { developing } \\
\text { countries. }\end{array}$ & $\begin{array}{l}\text { Islanded } \\
\text { mode }\end{array}$ & Low & $\begin{array}{c}\text { Maximum } \\
\text { power usage for } \\
\text { consumers is } \\
\text { limited. }\end{array}$ \\
\hline
\end{tabular}

Table 2. Causes of power quality problems related to DGs

\begin{tabular}{|c|c|c|c|}
\hline PQ issues & Wind power & Solar power & Hydro power \\
\hline Sag & Yes & No & Yes \\
\hline Swell & Yes & No & Yes \\
\hline Under voltage & Yes & No & No \\
\hline Over voltage & Yes & No & No \\
\hline Voltage unbalance & No & Yes & No \\
\hline Current harmonics & Yes & Yes & Yes \\
\hline Voltage harmonics & Yes & Yes & Yes \\
\hline Interruption & Yes & Yes & No \\
\hline
\end{tabular}

\section{F. Frequency variation}

When load increases more rapidly than the generator can react to adjust the power generation, it causes the generators to slow down. Then frequency is in fall condition and decreases when generation is higher than the load. In Fig.3, the utility user interfaces linear and nonlinear loads. In the power system operation, frequency variations are the major issue for power grid companies. An industrial application frequency variation has harmful effects on the modern computer controlled system as it can cause variable operation, system collapse, and computer equipment damage [21]. Generally, the frequency should be maintained based on grid standards. IEEE 1547-2003 standards, grid code fault ride through condition the output current of the grid converter maintains properly under balanced case [62].

\section{G. Voltage Transients}

The reason of disturbances is varied in power systems. An electrical transient is a short term excess of voltage/current in an electrical circuit which only lasts milliseconds, which can occur electrical, data and communication circuits. The transmission line switching, reactor and capacitor bank switching are the causes of power system switching events in voltage transients. IEC61000-4-30 determines the disturbances of transient occurrences should be finding the ability of transient event [63]. 


\section{H. Voltage unbalance and harmonics}

Voltage unbalance is one of the voltage related compensation. Low voltage (LV) microgrid, voltage unbalance is the general issue, where most of the loads are in single phase load. In literature [22], current and voltage harmonics are compensated by using the active filters. The further functions of active filters such as compensation of current and voltage unbalance, voltage flicker, voltage spikes. Rectifiers, inverters, switch mode power supplies, and energy saving lamps is the sources of harmonics which can easily appear in microgrid [23], but to mitigate the voltage distortion several recent inverters use filters which may give to harmonics at the user end to utilize power electronic based equipment. In [24, 25] voltage unbalance of DG output varies when the overall system changes after the disconnection of microgrid from the main grid. In an islanding mode of operation determines an output of the unbalanced three phase voltage exceeds the threshold value. The general equation of voltage unbalance at the observing time $t$ is given by,

$$
V U_{t}=\frac{N S_{t}}{P S_{t}}
$$

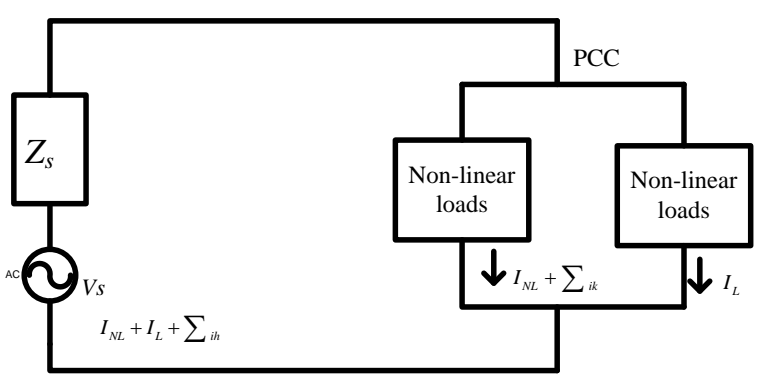

Fig.3. Utility interface [21].

Where $\mathrm{NS}_{\mathrm{t}}$ and $\mathrm{PS}_{\mathrm{t}}$ represent the magnitudes of the negative and positive sequence of the voltage at $t$. If negative sequence voltage can be eliminated then voltage harmonics should be affected and tedious calculation of threshold values are the major drawbacks. IEC recommends the voltage unbalance limits should be below 2\%. The characteristics of power quality phenomena have been identified in Table 3.

\section{HARMONIC DETECTION SCHEMES}

Harmonic Detection Schemes can be categorized into two types which include time domain methods and the frequency domain methods. Fast Fourier Transform (FFT), Discrete Fourier Transform (DFT), RMS voltage detection method, Sliding Discrete Fourier Transform (SDFT), the peak voltage detection method are the frequency domain methods [26].Synchronous Reference Frame (SRF) phase locked loop (PLL), Instantaneous reactive power and kalman filtering are the methods to remove the harmonic components from detecting the three-phase waveforms [27].

\section{A. RMS Voltage Detection Method}

In general, RMS is an equivalent value of dc voltage although RMS voltage is 0.707 times the peak voltage. The supply voltage of the RMS value and the comparison of the value is given to a threshold. An initial phase angle can depend on the residual voltages and durations, also detection capability and probabilistic performance are the negative aspects of RMS voltage methods [28]. The phase angle of supply voltage does not provide information in the event of RMS based methods. The RMS voltage can be derived by [29],

$$
V_{r m s}=\longdiv { \frac { 1 } { N } \sum _ { i = 1 } ^ { N } V ^ { 2 } [ i ] }
$$

$\mathrm{N} \rightarrow$ number of sampled points per cycle.

$\mathrm{V}[\mathrm{i}] \rightarrow \mathrm{i}^{\text {th }}$ sampled voltage.

If the $\mathrm{N}$ value becomes higher, then RMS value could be derived. The sampling $j$ of the RMS value can be computed by,

$$
V_{r m s}[j]=\longdiv { \frac { 1 } { N } \sum _ { i = 0 } ^ { N - 1 } V ^ { 2 } [ j - i ] }
$$

$$
\begin{aligned}
& \text { Assume } S[j]=\sum_{i=0}^{N-1} V^{2}[j-i] \text {, then } \\
& \qquad \begin{aligned}
S[j]-S[j-i] & =\sum_{i=0}^{N-1} V^{2}[j-i]-\sum_{i=0}^{N-1} V^{2}[j-i-1] \\
& =V^{2}[j]-V^{2}[j-N]
\end{aligned}
\end{aligned}
$$

So,

$$
S[j]=V^{2}[j]-V^{2}[j-N]+S[j-1]
$$

The disadvantage of this method is inaccurate calculation because of the low order harmonic distortion and the grid voltage variation ratio should be detected.

\section{B. Peak Voltage Detection Method}

An alternative method of RMS to detect voltage sag is the peak voltage method used for detecting voltage variation ratio of the grid. This peak voltage detection method can be expressed by,

$$
V_{\text {peak }}=\max |V(t-\tau)|, 0<\tau<t
$$

Where,

$$
\begin{array}{ll}
\mathrm{V}(\mathrm{t}-\tau) & \rightarrow \text { the sample grid voltage. } \\
\mathrm{t} & \rightarrow \text { the sampling interval } \\
\tau & \rightarrow \text { the instantaneous sample time. }
\end{array}
$$

When Low Voltage Ride Through (LVRT) operation is used to verify the ratio of grid voltage variation, the peak 
voltage detection method has limited use the half fundamental cycle. Likewise, low order harmonic distortion can detect inaccuracy calculation [57].

Table 3. Characteristics of power quality phenomena [65]

\begin{tabular}{|c|c|c|c|c|c|}
\hline Sl. No & Types & Duration & $\begin{array}{c}\text { Voltage } \\
\text { magnitude }\end{array}$ & $\begin{array}{c}\text { IEEE \& IEC } \\
\text { standards }\end{array}$ & References \\
\hline 1 & Voltage Sag & 0.5-30 period & $0.1-0.9 \mathrm{pu}$ & IEEE 519 & 60 \\
\hline 2 & Voltage Swell & 0.5-30 period & $1.1-1.8 \mathrm{pu}$ & IEEE 519 & 60 \\
\hline 3 & Short Interruption & 0.5-30 period & $<0.1 \mathrm{pu}$ & IEEE-1547 & 64 \\
\hline 4 & Under voltage variation & $>1 \mathrm{~min}$ & $0.8-0.9 \mathrm{pu}$ & IEC-61400 & 1,61 \\
\hline 5 & Over voltage variation & $>1 \mathrm{~min}$ & $1.1-1.2 \mathrm{pu}$ & IEC-61400 & 1,61 \\
\hline 6 & Sustained interruption & $>1 \mathrm{~min}$ & $0.0 \mathrm{pu}$ & IEC-61400 & 1,61 \\
\hline 7 & Voltage unbalance & Steady state & $0-0.1 \%$ & IEEE-1547 & 64 \\
\hline 8 & Harmonics & Steady state & $0-20 \%$ & IEC-61400 & 1,61 \\
\hline 9 & $\begin{array}{cc}\text { Impulsive transients } \\
\text { 1. } & \text { Nanosecond } \\
\text { 2. } & \text { Microsecond } \\
\text { 3. } & \text { Millisecond }\end{array}$ & $\begin{array}{c}<50 \mathrm{~ns} \\
50 \mathrm{~ns}-1 \mathrm{~ms} \\
>1 \mathrm{~ms}\end{array}$ & & IEC-61000-4-30 & 63 \\
\hline 10 & Frequency variation & & & IEEE $1547-2003$ & 62 \\
\hline
\end{tabular}

\section{Discrete Fourier Transform Method}

The purpose of DFT is to indicate in a time window to the sample signal in the harmonic components of the digital system. DFT is inaccurate for non - stationary signals [30]. The DFT can be defined as an equation (8),

$$
X(k)=\sum_{n=0}^{N-1} x(n) W N^{k n},(k=0,1,2, \ldots ., N-1)
$$

Where,

$$
W N=e^{\frac{-j 2 \pi}{N}}
$$

\section{Fast Fourier Transform Method}

Fourier Transform has a lot of limitations on the analysis of short time high frequency and long-time lowfrequency signals. Fast Fourier Transform (FFT) is a rapid algorithm of DFT and it decomposes the big point DFT into a small point DFT in this manner computational time can be reduced [31]. Information on the magnitude and phase angle of the harmonic components is provided by STFT during voltage waveform occurrence [30].

\section{E. Sliding Discrete Fourier Transform Method}

Sliding DFT is one among the essential tools for investigating the signals for the harmonic components; also sampling time on DFT performs an $\mathrm{N}$-point. It consists of two cascaded digital filters, combo filter proceeds from second order finite impulse response (FIR). The SDFT algorithm calculates the normalized frequency. The plus point of the SDFT is the simple structure and computational complexity has lower than the DFT and FFT. Z-domain transfer function of SDFT as defined in [32] is given below,

$$
H_{S D F T}(z)=\frac{e^{\frac{j 2 \pi k}{N} 1-z^{-N}}}{1-r e^{\frac{j 2 \pi k}{N z^{-1}}}}
$$

Where, $\mathrm{N}$ is the sample count, $\mathrm{k}$ is an integer represents $\mathrm{k}^{\text {th }}$ harmonic and $1-\mathrm{z}^{-}{ }^{\mathrm{N}}$ is the comb filter of FIR $\mathrm{H}(\mathrm{z})$ can be divided into real and imaginary parts.

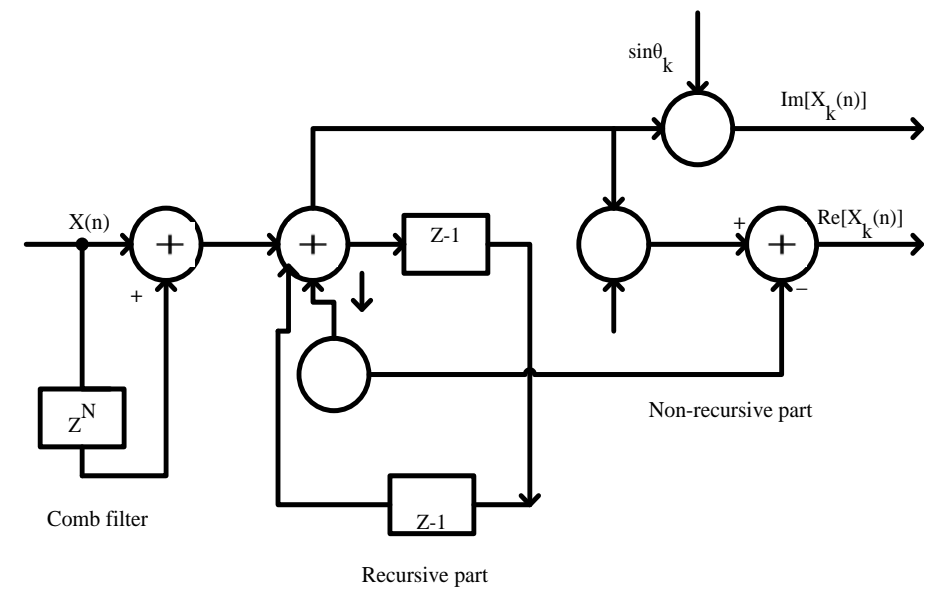

Fig.4. Structure of SDFT [33]. 


$$
\begin{aligned}
\operatorname{Re}[H(z)] & =\frac{1-z^{-N}\left(\cos \left(\frac{2 \pi k}{N}\right)-z^{-1}\right)}{1-2 \cos \left(\frac{2 \pi k}{N}\right) z^{-1}+z^{-2}} \\
\operatorname{Im}[H(z)] & =\frac{1-z^{-N}\left(\sin \left(\frac{2 \pi k}{N}\right)\right)}{1-2 \cos \left(\frac{2 \pi k}{N}\right) z^{-1}+z^{-2}}
\end{aligned}
$$

In the above equation, SDFT of real and imaginary parts can be generated using comb filter $\left(1-z^{-N}\right)$ and resonator. The schematic diagram of SDFT is shown in Fig. 4 [33].

\section{CONTROL METHODS IN MiCROGRIDS}

In $[34,35]$ repetitive controller is a simple learning control method which maintains low total harmonic distortion (THD) in load voltage and grid current. Also, it reaches smooth and continuous transfer of operation mode. In [58], the multilevel inverter is used to enhance the quality of voltage waveform with lower THD. Fig. 5 [36], represents the simplified diagram of a repetitive controller.

Harmonic droop control strategy [37] is performed for every individual harmonic, which maintains the difficulty in the reactive power at the different frequencies. Fig. 6 shows that the $h^{\text {th }}$ harmonic droop control. The $h^{\text {th }}$ harmonic frequency should be set as the frequency set point.

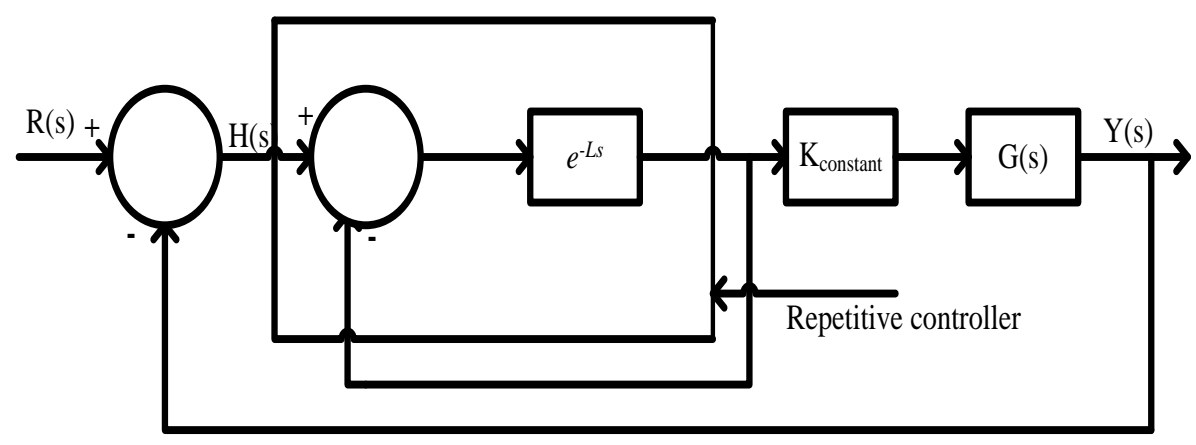

Fig.5. Repetitive controller [36].

The harmonic droop controller equation can be written as,

$$
\begin{gathered}
E_{h}=-n_{h} P_{h} \\
\omega_{h}=h \omega^{*}-m_{h} Q_{h}
\end{gathered}
$$

where, $\mathrm{P}_{\mathrm{h}}$ is the real power and $\mathrm{Q}_{\mathrm{h}}$ is the reactive power for $\mathrm{h}^{\text {th }}$ harmonic frequency and $\mathrm{n}_{\mathrm{h}}, \mathrm{m}_{\mathrm{h}}$ are the droop coefficients. The RMS value $\mathrm{E}_{\mathrm{h}}$ and phase angle to be formed by the $\mathrm{h}^{\text {th }}$ harmonic frequency at the reference voltage $V_{\text {rh }}$ generated from the combination of $\omega_{h}$. Harmonic frequency $\omega_{\mathrm{h}}$ from equation (13) can be combined to $-m_{h} n_{h}$ from $\omega_{h t}$ with adding the $\delta_{h}$, where $\omega_{t}$ phase of the voltage reference. It does not depend on the impedance of the output voltage but may also include resistive, inductive, capacitive or complex.

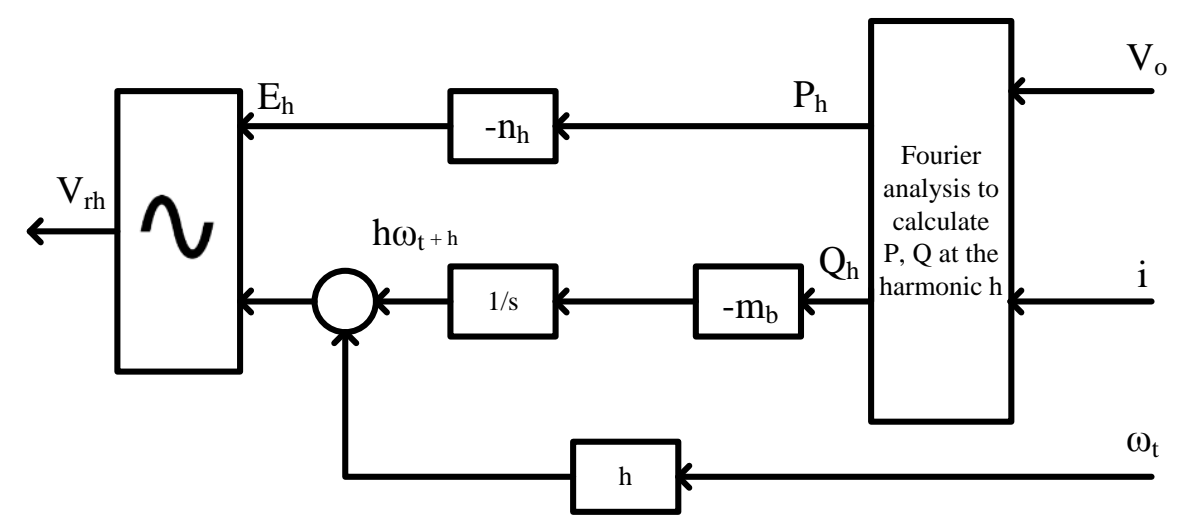

Fig.6. Harmonic droop control [37].

Generally, Adaptive virtual impedance control method $[38,39]$ is the power flow control method in low voltage distribution grids. Fig. 7 shows the basic arrangement of the adaptive virtual impedance control used to extract the positive and negative sequence at harmonic components. The positive sequence component and other current components cause for the resistive - inductive structure and resistive - capacitive virtual impedance and this 
performance of droop controllers is to exalt by the resistive - inductive virtual impedance. The resistive capacitive blocks provide proper sharing of load current among inverters of negative sequence and harmonic components. Actually, the resistive element improves damping of the system and inductive parts have decoupled real and reactive power [40]. In the low voltage distribution grid, droop controlled voltage source converter and reactive power sharing can increase the efficiency [39]. An important purpose of virtual impedance is the compensation of harmonics which can reduce the harmonics in the grid voltage.

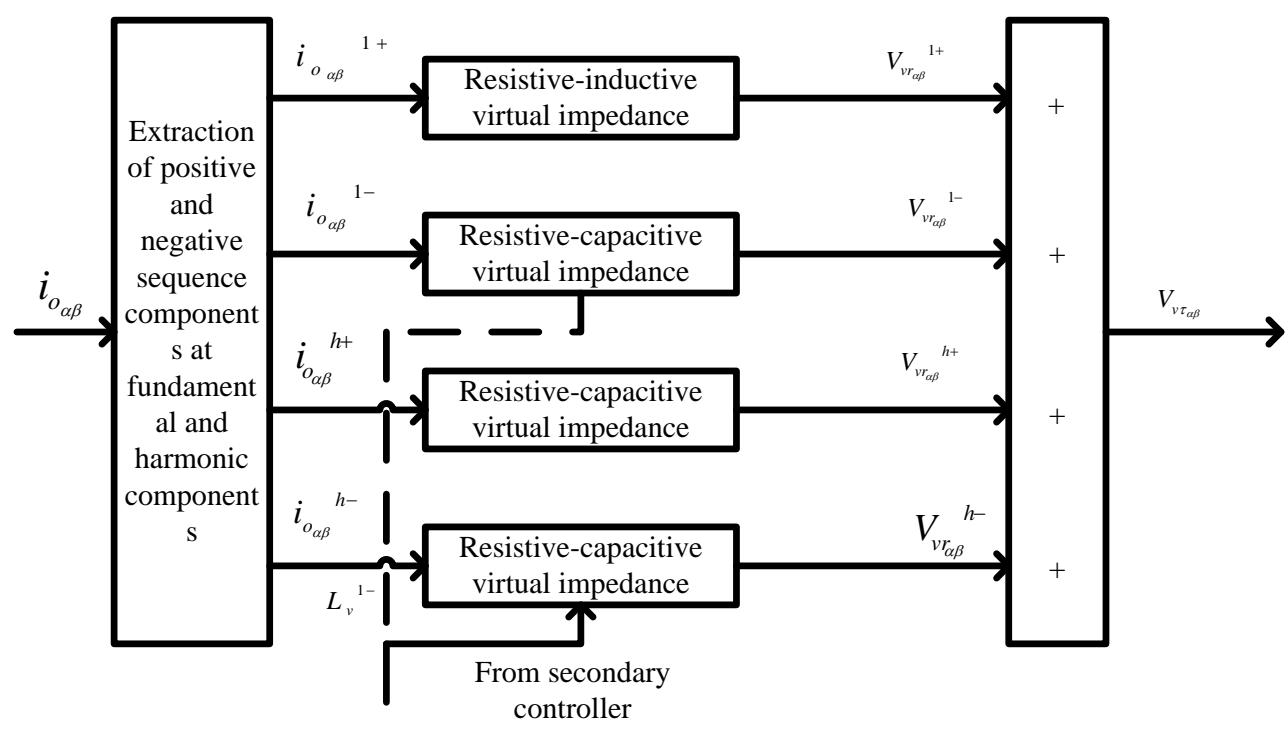

Fig.7. Adaptive virtual impedance.

The voltage controllers [41] adjust the inverter output voltage and it locates to the current controller. Proportional-integral (PI) controller, two degrees of freedom (2DOF) controller, resonant controller, hierarchical control, and repetitive controller are the several controllers used in the voltage controller design. The output voltages of the harmonic distortion while inverter supplies linear and non-linear loads are reduced by using these controllers. The parallel operation of inverters voltage droop control the power angle depends on active power and voltage difference on the reactive power [42].

$$
\begin{gathered}
f-f_{0}=K_{p}\left(P-P_{0}\right) \\
V_{s}-V_{0}=-K_{q}\left(Q-Q_{0}\right)
\end{gathered}
$$

In PI voltage control, the system response minimizes the steady-state error with its integral action. The two degree of freedom controller deals with the system deviation and reference variation. The major advantage of this technique is greater robustness. Hierarchical [43] control scheme is a common microgrid which consists of a primary and secondary control level. The DG local controllers act as the primary control and the central controller acts as the secondary control. This controller sends the reference signal to every DG's properly to reduce the voltage unbalance and harmonic distortion at the microgrid.

In [44], decoupling control scheme is suggested an electric spring (ES) in a microgrid is utilized for the active and reactive power flow control with variable and uncertain renewable energy. By adjusting the shift angle and amplitude of the modulation signal of the ES, the voltage dip and frequency deviation are improved. Integrated power quality controller (IPQC) [45] installed at PCC of the microgrid is recommended to reduce the voltage fluctuation, harmonic high penetration, bidirectional power flow and over current. To improve the source impedance to harmonics for the reason that primary winding shows the high impedance to harmonic also acts as a harmonic isolator. In literature [36], the resonant controller is based on the internal mode principle. It can be expressed as,

$$
C(s)=\frac{K_{1} \omega_{0}}{s^{2}}+\omega_{0}^{2}
$$


Table 4. Comparison of control techniques utilized in Microgrid Inverters

\begin{tabular}{|c|c|c|c|c|c|}
\hline Author & Ref.no & Year & Control & Merits & Demerits \\
\hline $\begin{array}{l}\text { Mario Herrán A } \\
\text { et al. }\end{array}$ & 35 & 2014 & $\begin{array}{l}\text { Repetitive } \\
\text { control }\end{array}$ & $\begin{array}{l}>\quad \text { Simple and efficient } \\
\text { learning algorithm. } \\
\text { It enables rejection of } \\
\text { signals with the high } \\
\text { harmonic. }\end{array}$ & $\begin{array}{l}\text { High current } \\
\text { distortion can show } \\
\text { with small } \\
\text { frequency changes. } \\
\text { Computational cost } \\
\text { is high. }\end{array}$ \\
\hline $\begin{array}{l}\text { Qing-Chang } \\
\text { Zhong et al, } \\
\text { Jinwei He et al. }\end{array}$ & $\begin{array}{l}37, \\
38\end{array}$ & $\begin{array}{l}2013 \\
2015\end{array}$ & $\begin{array}{l}\text { Harmonic droop } \\
\text { control }\end{array}$ & $\begin{array}{l}\text { Power sharing and droop } \\
\text { control must be reduced } \\
\text { an individual harmonic } \\
\text { frequency. } \\
\text { It avoids the complexity } \\
\text { of calculating the } \\
\text { reactive power. }\end{array}$ & $\begin{array}{l}\text { It may cause some } \\
\text { stability problems. }\end{array}$ \\
\hline Jinwei He et al. & 38,46 & $\begin{array}{l}2015 \\
2013\end{array}$ & $\begin{array}{l}\text { Adaptive virtual } \\
\text { impedance } \\
\text { control }\end{array}$ & $\begin{array}{l}\text { In the steady state } \\
\text { condition, reactive } \\
\text { power of microgrid, } \\
\text { power imbalance, } \\
\text { harmonic power sharing } \\
\text { should be compensated. } \\
\text { It reduces noises to the } \\
\text { DG units. }\end{array}$ & $\begin{array}{lr}\text { Total reactive } \\
\text { power demand has } \\
\text { somer variation } \\
\text { during the } \\
\text { compensation of } \\
\text { harmonic power } \\
\text { sharing error. }\end{array}$ \\
\hline $\begin{array}{l}\text { Mehdi } \\
\text { Savaghebi et al, } \\
\text { Jinwei He et al. }\end{array}$ & 43,47 & $\begin{array}{l}2012 \\
2015\end{array}$ & $\begin{array}{l}\text { Voltage control } \\
\text { method }\end{array}$ & $\begin{array}{l}\text { Less harmonic distortion } \\
\text { than the current injected } \\
\text { control. } \\
>\quad \text { Regulates DG unit when } \\
\text { feeder impedance } \\
\text { depends on virtual } \\
\text { impedance. }\end{array}$ & $\begin{array}{l}\text { Sufficient damping } \\
\text { to system resonance } \\
\text { is not provided. }\end{array}$ \\
\hline $\begin{array}{l}\text { Quoc- Nam } \\
\text { Trinh et al. }\end{array}$ & 48 & 2014 & $\begin{array}{c}\text { Hysteresis } \\
\text { control method }\end{array}$ & $\begin{array}{ll}> & \text { Simple structure. } \\
> & \text { Fast response. }\end{array}$ & $\begin{array}{l}\text { Switching noises in } \\
\text { supply current and } \\
\text { load voltage is } \\
\text { generated due to the } \\
\text { variation } \\
\text { frequency. } \\
\text { Control } \\
\text { performance is } \\
\text { limited. }\end{array}$ \\
\hline $\begin{array}{l}\text { Jiefeng Hu et al, } \\
\text { Ali Bidram et al. }\end{array}$ & 49,50 & $\begin{array}{l}2014 \\
2012\end{array}$ & $\begin{array}{l}\text { Virtual flux } \\
\text { droop control } \\
\text { method }\end{array}$ & 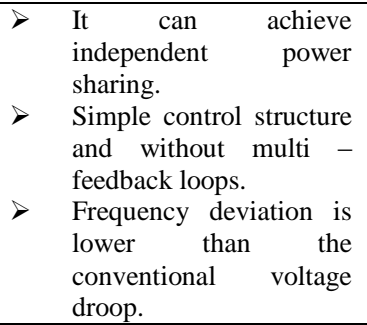 & $\begin{array}{l}>\text { Cannot handle } \\
\text { nonlinear loads. } \\
\text { Voltage regulation } \\
\text { is not surely } \\
\text { supported. }\end{array}$ \\
\hline $\begin{array}{l}\text { Mohammad S. } \\
\text { Golsorkhi et al. }\end{array}$ & 72 & 2016 & $\begin{array}{l}\text { Model } \\
\text { predictive } \\
\text { control }\end{array}$ & $\begin{array}{l}\text { It can improve the power } \\
\text { quality by the voltage } \\
\text { unbalance limits should } \\
\text { be below } 2 \% \text {. } \\
\text { Current harmonics } \\
\text { should be eliminated. }\end{array}$ & $\begin{array}{l}\text { During high loading } \\
\text { condition active } \\
\text { power and current } \\
\text { overloaded could be } \\
\text { prevented. }\end{array}$ \\
\hline
\end{tabular}

\section{OPTIMIZATION TECHNIQUES IN MiCROGRID}

In real-time, the optimization problem in a microgrid is a complicated concern. The system securities, optimal operation, and reduction of emission are the wide range of microgrid control that needs from one operating mode to other without violating system constraints [83]. The essential characteristics of microgrids are as follows:

In islanding mode of operation, the power quality and stability should be maintained and it requires improvement of control approach which needs to be both generation and distribution side.
Voltage and frequency control problems formed by the transitions from original operation to islanding mode of operation [51]. A brief overview of some of these optimization techniques is shown in table 5 .

Fen Tang et al [52], proposed a fundamental synchronization control (FSC) and distortion synchronization control (DSC) algorithms acts as a distributed actuators. In islanded mode, current controlled mode (CCM) and voltage controlled mode (VCM) voltage source converters are used for distributed storage (DS) provides power balance and voltage support. During distorted and unbalanced voltage conditions DSC algorithm is used to achieve a smooth reconnection. The 
important advantage of active synchronization is the simple design of parameters which include PLL structure. So, the voltage normalization is feasible.

Ali Maknouninejad et al [42] presented the cooperative distributed optimization to the DGs VAR generation control in a microgrid. The objective of this technique is to minimize the total voltage across the microgrid. The minimization of cost function can be written as,

$$
\sum_{i=1}^{N} f_{i}, f_{i}=\left(\frac{1}{2}\right)\left(1-V_{i}\right)^{2}
$$

The benefits of this optimization technique are the minimization of losses and unified voltage profile. Also, it is possible to determine the low active power losses and stability analysis.

Alessandra Parisio et al $[53,54]$ implemented a mixed integer linear programming (MILP), a model predictive control (MPC) approach of optimization in microgrid operation. MPC - MILP control economically optimizes the microgrid operation and computational burden by using commercial solvers without decomposition techniques. The application of MPC is to prediction models, operation and security constraints.

Saeed Jazebi et al [55], proposed a shuffled frog leaping algorithm (SFLA) and imperialist competitive algorithm (ICA) are used with discrete particle swarm optimization (DPSO).

Authors proved that the harmonic losses might be reduced after reconfiguration, whereas voltage and current deviation could be satisfied.

Yixi Zhu et al [56] developed a virtual impedance control to determine with the help of genetic algorithm (GA) optimized to reduce the reactive power sharing error. Also, DG units share the loads in MG network that is unbalanced power and harmonic power.

In literature [67], the performance of particle swarm optimization (PSO) algorithm is based on the evolution of particle and combination of the swarm. The equations of search rule with respect to position vector $X_{i}$ and velocity vector $V_{i}$ can be expressed by,

$$
\begin{gathered}
V_{i}^{k+1}=\omega V_{i}^{k}+c_{1} r d_{1}\left(X_{p} b_{i}^{k}-X_{i}^{k}\right)+c_{2} r d_{2}\left(X_{g} b^{k}-X_{i}^{k}\right) \\
X_{i}^{k+1}=X_{i}^{k}+V_{i}^{k+1} \\
\omega=\omega_{\max }-\frac{k \cdot\left(\omega_{\max }-\omega_{\min }\right)}{N}
\end{gathered}
$$

where $c_{1}, c_{2}$ are positive constants; $\omega$ is the weight of inertia; $\mathrm{N}$ is the total number of iterations; and $\mathrm{X}_{\mathrm{p}} \mathrm{b}_{\mathrm{i}}{ }^{\mathrm{k}}$, $\mathrm{X}_{\mathrm{g}} \mathrm{b}^{\mathrm{k}}$ are the best positions based on its own experience. The optimal solution of search space near the boundaries should be difficult to shows the restrictions and limitations on the parameters. Therefore, the damped reflecting method is used to solve the optimal problem near the boundaries which is more consistent and robust $[84,85]$.

The designs of the inverter- output- controller optimization have to be rejecting the variation of frequency and voltage disturbances in the microgrid. The principle of controller design should be stable under undisturbed closed-loop system and control of the inverter bandwidth should be a wide range of reference output power. The closed loop controller can be obtained as

$$
\begin{gathered}
\tilde{x}(t)=A_{c 1} \tilde{x}(t)+B_{c 1} \omega(t) ; \tilde{x}(0)=0 \\
y(t)=C_{c 1} \tilde{x}(t)+D_{c 1} \omega(t)
\end{gathered}
$$

In the stability criterion, closed loop poles are located in the left half plane which means the matrix $A_{c l}$ must be Hurwitz. In closed loop system the eigenvalue of s plane is achieved by the controller criterion, also the convolution operator of $\mathrm{L}_{1}$ can be minimized by the performance criterion. The $\mathrm{L}_{1}$ theory of convolution operator can be expressed as

$$
\|G\|_{1}=\sup _{\omega L \infty} \frac{\|y\|_{\infty, \infty}}{\|y\|_{\infty, 2}}
$$

The above equation can be represented by reducing the frequency and voltage disturbances to control the current performance of the inverter. $\|\mathrm{G}\|_{1}$ has bounded that the closed loop controls system, if the stability criterion is satisfied. This PSO for the inverter controller techniques is only considered the PI controller parameters and it needed more improvement.

In the droop-controller optimization an operation of microgrid should be more efficient and stability of the output of DG control, the reason can be minimized an integrated error cost function with small signal steady state errors. In this optimization technique, the objective function of minimizing an error cost function is integrated time-weighted squared error (ITAE). The operating conditions of stability criterion can be considered as the three conditions such as grid-connected mode $\left(\mathrm{J}_{1}\right)$, the transition period between grid-connected and islanded mode $\left(\mathrm{J}_{2}\right)$ and islanded mode $\left(\mathrm{J}_{3}\right)$. The equation of cost function can be expressed as

$$
J=\sum_{i=1}^{3} J_{i}=\sum_{i=1}^{3}\left[\sum_{k=k_{0}{ }^{\tau}}^{k_{f}{ }^{\tau}}\left[k-k_{0}{ }^{i}\right] \cdot W \cdot\left|E^{i}(k)\right|\right]
$$

where $\tau$ is the performance of the control index, $\mathrm{k}$ is the sampling period, $\mathrm{W}$ is the matrix of the weighting element. The matrix of absolute error $\mathrm{E}^{\mathrm{i}}(\mathrm{k})$ can be represented as,

$$
E^{i}(k)=\left[\Delta_{P}^{i}(k), \Delta_{Q}^{i}(k), \Delta_{\text {freq }}{ }^{i}(k)\right]^{T}
$$

The measurements and references of real and reactive power error can be determined as $\Delta \mathrm{P}^{\mathrm{i}}(\mathrm{k})$ and $\Delta \mathrm{Q}^{\mathrm{i}}(\mathrm{k})$, $\Delta \mathrm{V}^{\mathrm{i}}(\mathrm{k})$ is the voltage deviation and $\Delta$ freq $^{\mathrm{i}}(\mathrm{k})$ is the frequency deviation from the per unit (p.u.) value. In this 
technique normally, the p.u. value is 1.0 p.u. The parameters of actual droop control power sharing between DG's can be explained as

$$
\begin{gathered}
R_{i}=R_{o} . r_{i} \\
M_{i}=M_{o} . m_{i}
\end{gathered}
$$

Therefore the power sharing between DG becomes the ratio of real power is $1 / 5: 1 / 7$ and ratio of reactive power are $1: 1$. The amount of power sharing between real and reactive power using droop controllers in a microgrid system should be quickly stable in nature.

In [68], optimization based on genetic algorithm (GA) was proposed to improve the stability and easily switching the operation of different modes in a microgrid. The dynamic performance of optimization objective function can be obtained as

$$
\min J=\sum_{i=1}^{M}\left\{\int_{t=t_{o}^{i}}^{t_{t}^{i}}\left(t-t_{o}^{i}\right)\left[\left(P(t)-P^{*}(t)\right)^{2}+\left(Q(t)-Q^{*}(t)\right)^{2}\right] d t\right\}
$$

where $P(t), Q(t)$ are the real and reactive power in the various operation mode, $M$ is the microgrid operation mode, $t_{o} i$ is the start time in $i$ and $t_{f} i$ is end time in $i$. The characteristic of GA is global search, stochastic, adaptive and parallel applicable for solving the optimization problem in the nonlinear system. Control parameters for microgrid $\mathrm{X}=\left[m_{p}, n_{q}, K_{p u}, K_{i c}\right]$ which is affecting that small signal steady state stability and high sensitive performance also, control parameters can act as optimal variables. The flowchart of microgrid optimization of a genetic algorithm as shown in Fig.8.

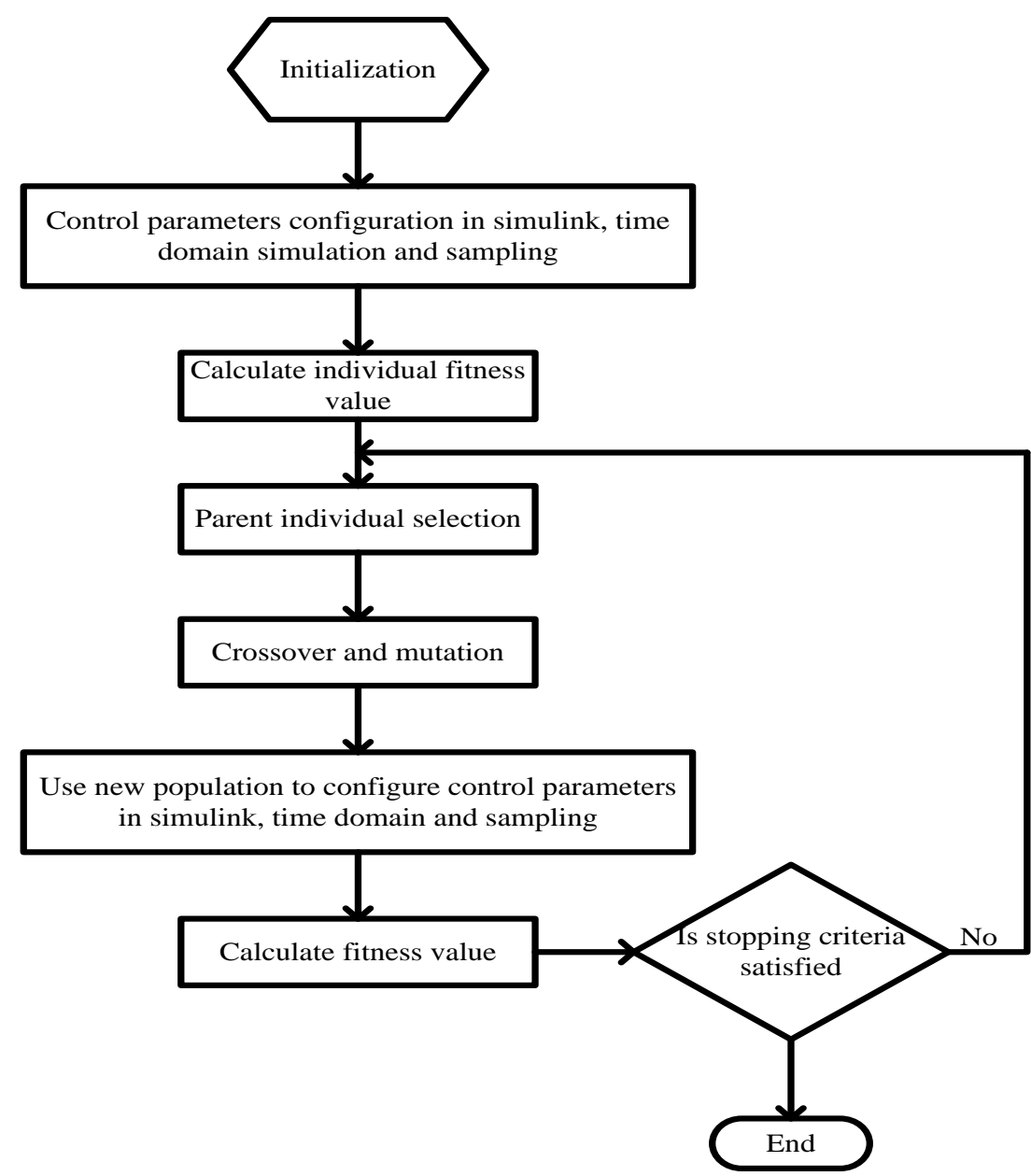

Fig.8. Flowchart of genetic algorithm optimization process.

In [69], consensus algorithm based distributed control methods for DC micro grids was proposed to attain the sharing of information and coordinate multiple distribution units. Consensus algorithm contains continuous control domain and discrete control domain, the model of continuous time (CT) has more accuracy and discrete time (DT) model can act as a digital communication control network. The continuous and discrete time integrator of consensus algorithm can be expressed as,

$$
\dot{x}_{i}(t)=\sum_{j \in N_{i}} a_{i j} \cdot\left(x_{j}(t)-x_{i}(t)\right)
$$




$$
x_{i}(k+1)=x_{i}(k)+\varepsilon \cdot \sum_{j \in N_{i}} a_{i j} \cdot\left(x_{j}(k)-x_{i}(k)\right)
$$

where, $N_{i}$ is the set of agents connected with $i, \varepsilon$ is the constant weight of the edge, $a_{i j}$ is the connection between the node $i$ and $j$. To conclude the features of control algorithm have more accuracy for sharing of current, the speed of the system should be a high response.

\section{MicrogRid ApPlicAtions In RENEWABle ENERGY}

The application of the AC-DC converter in the wind turbines is generally used in islanding operation of DC converters. The DC grid is constructed for both high voltage and low voltage that is called as LVDC grid, it requires regulation of voltage and power control process should act as the load side control [70]. In DG wind turbine generator is significantly used in the wind power generation systems. In literature [71], the cause of wind speed variation is the fluctuations of power that can be affected by the frequency and voltage stability where the stability of the generated power fluctuation should be controlled by fast and robust methods. The improvement of real and reactive power has control by different approaches to transmitting the output power to the grid with energy storage system (ESS) solutions. The applications of wind power generation systems and hybrid renewable energy sources vanadium redox flow battery (VRB) based ESS systems were used in Australia and Japan. Low maintenance cost, quick response, high capacity is the major advantages of VRB.

Table 5. Optimization methods for power quality improvement in microgrid

\begin{tabular}{|c|c|c|c|c|}
\hline References & $\begin{array}{c}\text { Year of } \\
\text { publication }\end{array}$ & $\begin{array}{c}\text { Category of } \\
\text { optimization }\end{array}$ & Method of optimization & Objectives \\
\hline 74 & 2013 & PSO & $\begin{array}{l}\text { Particle swarm optimization for } \\
\text { control }\end{array}$ & $\begin{array}{l}\text { To regulate the power sharing between the } \\
\text { microgrid and utility under variable load } \\
\text { conditions [74]. }\end{array}$ \\
\hline 75 & 2013 & $\mathrm{PSO}$ & $\begin{array}{l}\text { Particle swarm optimization for } \\
\text { frequency and voltage regulation }\end{array}$ & $\begin{array}{l}\text { When the microgrid is operated in islanded } \\
\text { condition harmonic distortion, voltage and } \\
\text { frequency regulation, power sharing, steady } \\
\text { state response and dynamic state response } \\
\text { are the parameters could be optimized [75]. }\end{array}$ \\
\hline 76 & 2010 & PSO & $\begin{array}{l}\text { Particle swarm optimization } \\
\text { based PWM inverter }\end{array}$ & $\begin{array}{l}\text { Using selective harmonic elimination (SHE) } \\
\text { technique low order harmonics are } \\
\text { eliminated [76]. }\end{array}$ \\
\hline 77 & 2013 & PSO & $\begin{array}{l}\text { Particle swarm optimization for } \\
\text { stability analysis }\end{array}$ & $\begin{array}{l}\text { To achieve the stability of the microgrid } \\
\text { using the minimization of power error based } \\
\text { on PSO [77]. }\end{array}$ \\
\hline 78 & 2016 & GA & $\begin{array}{l}\text { Non-dominated sorting genetic } \\
\text { algorithm II (NSGA-II) }\end{array}$ & $\begin{array}{l}\text { To protect the capability of the grid } \\
\text { connected microgrid given by the demand } \\
\text { response and to improve the voltage } \\
\text { stability of the microgrid [78]. }\end{array}$ \\
\hline 79 & 2016 & $\mathrm{HS}+\mathrm{GA}$ & $\begin{array}{l}\text { Harmony search (HS) and } \\
\text { genetic algorithm }\end{array}$ & $\begin{array}{l}\text { To improve the voltage profile, reduction of } \\
\text { power loss and increase the reliability based } \\
\text { on HS via genetic algorithm [79]. }\end{array}$ \\
\hline 68 & 2016 & GA & Genetic algorithm & $\begin{array}{l}\text { To achieve the stability of the microgrid } \\
{[68]}\end{array}$ \\
\hline 69 & 2016 & $\mathrm{CA}$ & Consensus algorithm & $\begin{array}{l}\text { The objective of the consensus algorithm is } \\
\text { to voltage restoration and accurate sharing } \\
\text { of current in distributed generation [69]. }\end{array}$ \\
\hline 80 & 2013 & $\mathrm{ACO}$ & Ant colony optimization & $\begin{array}{l}\text { When microgrid is operated in autonomous } \\
\text { mode which maintains the voltage and } \\
\text { frequency of the microgrid within the limits } \\
\text { and minimize the THD [80] }\end{array}$ \\
\hline 55 & 2014 & SFLA & $\begin{array}{c}\text { Shuffled - frog leaping } \\
\text { algorithm }\end{array}$ & To reduce harmonic losses [55]. \\
\hline 81 & 2016 & SFLA + FPD & $\begin{array}{l}\text { Shuffled - frog leaping agorithm } \\
\text { + Fuzzy pareto dominance }\end{array}$ & $\begin{array}{l}\text { FPD and SFLA is used to solve the multi- } \\
\text { objective optimization problem in } \\
\text { distribution system. To minimize power } \\
\text { loss, voltage sag and THD [81]. }\end{array}$ \\
\hline 82 & 2013 & MRGN & $\begin{array}{l}\text { Modified recursive guass } \\
\text { newton algorithm }\end{array}$ & $\begin{array}{l}\text { Minimization of error cost function between } \\
\text { observed and estimated signal[82]. }\end{array}$ \\
\hline
\end{tabular}

\section{DISCUSSION AND FUTURE VISION}

Some of the research opportunities in this area which will have an impact on power quality issues and renewable energy system are given below. The generated power from renewable energy sources will be utilized such as solar PV, the wind, battery energy storage system, etc. should be extended possible [86]. The droop control techniques are based on the measurement of state variable networks. These state variables are mainly used to distribute the distributed generation because they avoid the dangerous communication link [87]. In the overall review, adaptive droop control method provides better sharing of reactive power and voltage regulation. The control strategies of microgrid can be decided the issues 
are mentioned by the various topics.

$>$ Integration of RES: The performance of RES such as solar, wind, etc. with droop control methods has a poor response. But we can modify the existing droop control methods to improve the performance of the RES.

$>$ Stability problem: Stability issues such as complex loads, pulsed loads cannot achieve by using the existing droop control methods. The modify droop control techniques should mitigate the problems such as voltage regulation, the frequency of complex loads.

\section{CONCLUSION}

This paper presents a review on power quality impacts due to harmonic distortion in a microgrid. The current issues owing to the challenges in grid side power quality and microgrid control methods are discussed in this review. The merits and demerits of the controllers utilized in microgrid operation are discussed in detail. Intelligent optimization techniques to improve the microgrid control and operation are focused in detail. This review aims to throw light on the various control strategies available, the operation and performance of the control techniques and the optimization strategies available to improve the performance of control owing to the increasing need and growth of microgrids in future. A model predictive control could satisfy the power quality improvement such as voltage unbalance, total harmonic distortion, stability margin, dynamic performance of islanded microgrids. The heuristic optimization techniques such as PSO, GA, CA, MRGN algorithms are implemented to optimize the lifetime and to maximize the efficiency of the microgrid system. The shortcomings if the technical challenges in the review met will lead to accurate, self-sustained, and reliable quality future grid.

\section{REFERENCES}

[1] Mohod, S.W., and Aware,M.V., "A STATCOM-control scheme for grid connected wind energy system for power quality improvement", IEEE systems journal.,vol. 4(3): pp.346-352, 2010.

[2] Dash, P.K., Padhee, M., Barik, S.K., "Estimation of power quality indices in distributed generation systems during power islanding conditions", International Journal of Electrical Power \& Energy Systems, vol.36(1): pp.18-30. 2012.

[3] Khokhar, Suhail., Abdullah Asuhaimi, B., Mohd Zin., Ahmad Safawi B. Mokhtar., and Mahmoud Pesaran., "A comprehensive overview on signal processing and artificial intelligence techniques applications in classification of power quality disturbances", Renewable and Sustainable Energy Reviews, vol. 51 : pp.1650-1663, 2015.

[4] Zeng, Z., Yang, H., Tang, S., and Zhao, R., “Objectiveoriented power quality compensation of multifunctional grid-tied inverters and its application in microgrids", IEEE Transaction on Power Electronics, vol. 30(3): pp. 12551265, 2015.
[5] Phipps., James K., John P. Nelson., and Pankaj K. Sen., "Power quality and harmonic distortion on distribution systems", IEEE transactions on industry applications, vol. 30(2) : pp. 476-484, 1994.

[6] Li Y., Vilathgamuwa, D.M., Loh, P.C., "Microgrid power quality enhancement using a three-phase four-wire gridinterfacing compensator", IEEE Transaction on Industry Applications, vol. 41(6): pp. 1707-1719, 2005.

[7] Majumder, R., "Reactive power compensation in singlephase operation of microgrid", IEEE Transaction on Industrial Electronics, vol. 60(4): pp. 1403-1416, 2013.

[8] Parhizi, Sina., Hossein Lotfi., Amin Khodaei., and Shay Bahramira.,. "State of the art in research on microgrids: A review", IEEE Access, 3: pp. 890-925, 2015.

[9] Milczarek, A., Malinowski, M., Guerrero, J. M., "Reactive power management in islanded microgrid proportional power sharing in hierarchical droop control", IEEE Transaction on Smart Grid, vol. 6(4): pp. 16311638, 2015.

[10] Vandoorn., Tine L., Jeroen De Kooning., Bart Meersman., and Lieven Vandevelde., "Voltage-based droop control of renewables to avoid on-off oscillations caused by overvoltages." IEEE Transactions on Power Delivery, vol. 28(2): pp. 845-854, 2013.

[11] Khadem, S.K., Basu, M., and Conlon, M.F., "Power quality in grid connected renewable energy systems : role of custom power devices”, In: Conference on Renewable Energies and Power Quality (ICREPQ'10), Spain, 23-25 March 2010.

[12] Mahela, O.P., Shaik, A.G., Gupta, N.A., " Critical review of detection and classification of power quality events", Renewable and Sustainable Energy Reviews, vol. 41: pp. 495 -505, 2015.

[13] Pathak, A.K., Sharma, M.P., Bundele, M., "A critical review of voltage and reactive power management of wind farms", Renewable and Sustainable Energy Reviews, vol. 51: pp. $460-471,2015$.

[14] Bollen, M.H.J., "What is power quality?", Electric power systems research, vol. 66: pp. 5 -14, 2003.

[15] Yan., Xiangwu., Giri Venkataramanan., Patrick S. Flannery., Yang Wang., Qing Dong., and Bo Zhang., "Voltage-sag tolerance of DFIG wind turbine with a series grid side passive-impedance network", IEEE Transactions on Energy Conversion, vol. 25(4): pp. 10481056, 2010.

[16] Power Standards lab, Voltage Sags (Dip) and Swells, 2012.

[17] Yilmaz, I., Ermiş, M., and Çadirci, I., "Medium frequency induction melting furnace as a load on the power system", IEEE Transaction on Industry Applications, vol. 48(4): pp. 1203-1214, 2012.

[18] Juan, C., Cebrian., and Nelson Kagan., "Hybrid method to assess sensitive process interruption costs due to faults in electric power distribution networks", IEEE Transaction on Power Delivery, vol. 25(3): vol. 1686 - 1696, 2010.

[19] Antonio Moreno - Munoz., "Power Quality: Mitigation Technologies in a Distributed Environment", Springer Science \& Business Media, 1994.

[20] Arindam Ghosh., and Gerard Ledwich., "Power quality enhancement using custom power devices", Springer science \& business media, pp. 27-54, 2012.

[21] Wilson Kazibwe, E., and Musoke Sendaula, H., "Electrical power quality control techniques, Springer science \& business media, pp. 1-223, 1993.

[22] Singh, B., Al-Haddad, K., and Chandra A., "A review of active filters for power quality improvement", IEEE Transaction on Industrial Electronics, vol. 46(5): pp. 960- 
971, 1999.

[23] Merino., Julia., Patricio Mendoza-Araya., Giri Venkataramanan., and Mustafa Baysal., "Islanding detection in microgrids using harmonic signatures." IEEE Transactions on Power Delivery vol. 30(5): pp. 21022109, 2015

[24] Li, Canbing., Chi Cao., Yijia Cao., Yonghong Kuang., Long Zeng., and Baling Fang., "A review of islanding detection methods for microgrid", Renewable and Sustainable Energy Reviews, vol. 35: pp. 211-220, 2014.

[25] Sung-Il Jang., Kwang-Ho Kim., "An Islanding detection method for distributed generations using voltage unbalance and total harmonic distortion of current", IEEE Transaction on Power Delivery,vol. 19(2): pp. 745 -752, 2004.

[26] Wang, Y.F., and Li, Y.W., "A grid fundamental and harmonic component detection method for single-phase systems", IEEE Transaction on Power Electronics, vol. 28(5): pp. 2204-2213, 2013.

[27] Jowder, F.A.L., "Design and analysis of dynamic voltage restorer for deep voltage sag and harmonic compensation", IET Generation, Transmission \& Distribution, vol. 3(6): pp. 547- 560, 2009.

[28] Moschitta, A., Carbone, P., and Muscas, C., "Generalized likelihood ratio test for voltage dip detection", IEEE Transaction on Instrumentation and Measurement, vol. 60(5): pp.1644-1653, 2011.

[29] Cong, M., Feng, G., Guoqing, H., and Guanghui Li ., "A voltage detection method for the voltage ride- operation of renewable energy generation systems under grid voltage distortion conditions", IEEE Transaction on Sustainable Energy, vol. 6(3): pp. 1131-1139, 2015.

[30] Perez, E., and Barros, J., "Voltage event detection and characterization methods: A comparative study", IEEE / PES Transmission \& Distribution Conference and Exposition, Latin America, 15- 18 : pp.1-6, 2006.

[31] WeiHui Zou., and ShiPing Su., "Voltage flicker detection based on wavelet fourier transform", In: Proceedings of Electrical and Control Engineering (ICECE), Yichang, 1618: pp.4218- 4220, 2011.

[32] Abdulaziz Alkuhayli., Ali Safayet., and Iqbal Husain., "Single-phase distributed generation synchronization with a distorted or weak grid", In: Proceedings of IEEE Energy Conversion Congress and Exposition ECCE, Montreal, 20-24: pp. 1143 - 1148, 2015.

[33] Sumathi, P., and Janakiraman, P.A., "Integrated phaselocking scheme for SDFT-based harmonic analysis of periodic signals", IEEE Transaction on Circuits and Systems II: Express Briefs, 16: vol. 55(1): pp. 51-55, 2008.

[34] Qing-Chang Zhong., and Tomas Hornik., "Cascaded current-voltage control to improve the power quality for a grid-connected inverter with a local load", IEEE Transaction on Industrial Electronics, vol.60(4) : pp.1344 $-1355,2013$.

[35] Herran, Mario A., Jonatan Roberto Fischer., Sergio Alejandro Gonzalez., Marcos Gabriel Judewicz., Ignacio Carugati., and Daniel O. Carrica., "Repetitive control with adaptive sampling frequency for wind power generation systems", IEEE Journal of Emerging and Selected Topics in Power Electronics, vol.2(1): pp. 58-69, 2014.

[36] Xu, Ming Xia., Dehong Xu., Ping Lin., Min Chen., Jianxun Ni., and Tao Zhang.,"Understanding repetitive control and resonant control", In Power Electronics for Distributed Generation Systems (PEDG), 2012 3rd IEEE International Symposium on, pp. 621-627, 2012.

[37] Qing-Chang Zhong., "Harmonic droop controller to reduce the voltage harmonics of inverters", IEEE Transaction on Industrial Electronics, vol. 60(3): pp. 936 945, 2013.

[38] Jinwei He., Yun Wei Li., and Frede Blaabjerg., "An enhanced islanding microgrid reactive power, imbalance power, and harmonic power sharing scheme", IEEE Transaction on Power Electronics, vol. 30(6): pp. 3389 3401, 2015.

[39] Savaghebi, Mehdi., Qobad Shafiee., Juan C. Vasquez., and Josep M. Guerrero.,"Adaptive virtual impedance scheme for selective compensation of voltage unbalance and harmonics in microgrids", In Power \& Energy Society General Meeting, 2015 IEEE, pp. 1-5, 2015.

[40] Savaghebi, Mehdi., Juan C. Vasquez., Alireza Jalilian., Josep M. Guerrero., and Tzung- Lin Lee., "Selective harmonic virtual impedance for voltage source inverters with LCL filter in microgrids", In Energy Conversion Congress and Exposition (ECCE), 2012 IEEE, pp. 19601965, 2012.

[41] Ortega., Rubén, E., Figueres, G., Garcerá, C. L. Trujillo., and D. Velasco., "Control techniques for reduction of the total harmonic distortion in voltage applied to a singlephase inverter with nonlinear loads: Review", Renewable and Sustainable Energy Reviews,16(3): pp. 1754-1761, 2012.

[42] Maknouninejad, A., and Qu, Z., "Realizing unified microgrid voltage profile and loss minimization: cooperative distributed optimization and control approach", IEEE Transaction on Smart Grid, vol. 5(4): pp. 1621-1630, 2014.

[43] Savaghebi, Mehdi., Alireza Jalilian., Juan C. Vasquez., and Josep M. Guerrero.,"Secondary control for voltage quality enhancement in microgrids", IEEE Transactions on Smart Grid, vol. 3(4) :pp. 1893-1902, 2012.

[44] Chen., Xia., Yunhe Hou., Siew-Chong Tan., Chi-Kwan Lee., and Shu Yuen Ron Hui., "Mitigating voltage and frequency fluctuation in microgrids using electric springs", IEEE Transactions on Smart Grid, vol. 6(2): pp. 508-515, 2015

[45] Dayi Li., Zhu, Z.Q., “A Novel integrated power quality controller for microgrid", IEEE Transaction on Industrial Electronics, vol. 62(5): pp. 2848 - 2858, 2015.

[46] Jinwei He., Yun Wei Li., and Frede Blaabjerg., “An accurate autonomous islanding microgrid reactive power, imbalance power and harmonic power sharing scheme", In: Proceedings of IEEE Energy Conversion Congress and Exposition, Denver, pp.1337-1343, 2013.

[47] He., Jinwei., Yun Wei Li., Ruiqi Wang., and Chenghui Zhang., "Analysis and mitigation of resonance propagation in grid-connected and islanding microgrids", IEEE Transactions on Energy Conversion, vol. 30(1): pp. 70-81, 2015.

[48] Quoc- Nam Trinh., and Hong- Hee Lee., "Improvement of unified power quality conditioner performance with enhanced resonant control strategy", IET Generation,Transmission \& Distribution, vol. 8(12): pp. $2114-2123,2014$.

[49] Jiefeng Hu., Jianguo Zhu., and David G Dorrell., "Virtual flux droop method-a new control strategy of inverters in microgrids", IEEE Transaction on Power Electronics, vol. 29(14): pp. 4704 - 4711, 2014.

[50] Ali Bidram., and Ali Davoudi., "Hierarchical structure of microgrids control system", IEEE Transaction on Smart Grid, vol. 3(4): pp. 1963 - 1976, 2012.

[51] Narkhede, Mahesh S., S. Chatterji., and Smarajit Ghosh., "Trends and challenges in optimization techniques for operation and control of Microgrid-A review", In Power 
and Energy in NERIST (ICPEN), 2012 1st International Conference on, pp. 1-7, 2012.

[52] Tang., Fen., Josep M. Guerrero., Juan C. Vasquez., Dan Wu., and Lexuan Meng., "Distributed active synchronization strategy for microgrid seamless reconnection to the grid under unbalance and harmonic distortion", IEEE Transactions on Smart Grid, vol. 6(6): pp. 2757-2769, 2015.

[53] Alessandra Parisio., Evangelos Rikos., and Luigi Glielmo., "A model predictive control approach to microgrid operation optimization", IEEE Transaction on Control Systems Technology, 22(5): 1813 - 1827, (2014).

[54] Ouammi., Ahmed., Hanane Dagdougui., Louis Dessaint., and Roberto Sacile., "Coordinated model predictive-based power flows control in a cooperative network of smart microgrids", IEEE Transactions on Smart grid, vol. 6(5) : pp. 2233-2244, 2015.

[55] Saeed Jazebi., Moosa Moghimi Hadji., and Ramezan Ali Naghizadeh., "Distribution network reconfiguration in the presence of harmonic loads: optimization techniques and analysis", IEEE Transaction on Smart Grid, vol. 5(4): pp. 1929 - 1937, 2014

[56] Zhu., Yixin., Fang Zhuo., Feng Wang., Baoquan Liu., Ruifeng Gou., and Yangjie Zhao.,"A virtual impedance optimization method for reactive power sharing in networked microgrid", IEEE Transactions on Power Electronics, vol. 31(4): pp. 2890-2904, 2016.

[57] Amalorpavaraj, Rini Ann Jerin., Palanisamy, K., Umashankar, S., and Thirumoorthy, A. D., "Power Quality Improvement of Grid Connected Wind Farms through Voltage Restoration Using Dynamic Voltage Restorer", International Journal of Renewable Energy Research, vol. 6(1): pp. 53-60, 2016.

[58] Prabaharan, N., and Palanisamy, K., "Investigation of single phase reduced switch count asymmetric multilevel inverter using advanced pulse width modulation technique",International Journal of Renewable Energy Research, vol. 5(3): pp. 879-890, 2015.

[59] Lasseter, R.H., "MicroGrids", In: Proceedings of IEEE Power Engineering Society Winter Meeting, USA, 27-31, pp. 305-308, 2002.

[60] Soma Biswas., Swapan Kumar Goswami., and Amitava Chatterjee., "Optimal distributed generation placement in shunt capacitor compensated distribution systems considering voltage sag and harmonics distortions", IET Generation, Transmission \& Distribution, vol. 8(5): pp. 783-797, 2014

[61] Ghorbanian, M. J., Goodarzvand, F., Pourdaryaei, A., and WN L. Mahadi., "Mitigating voltage sag by implementing STATCOM on DFIG-based wind farms connected to a power system" In Engineering Technology and Technopreneuship (ICE2T), $2014 \quad 4^{\text {th }}$ International Conference on, pp. 131-136, 2014.

[62] Andres E. Leon., and Jorge, A. Solsona., "Performance improvement of full-converter wind turbines under distorted conditions", IEEE Transaction on Sustainable Energy, vol. 4(3): pp. 652-660, 2013.

[63] Antonio Cataliotti., Valentina Cosentino., and Salvatore Nuccio., "A phase-locked loop for the synchronization of power quality instruments in the presence of stationary and transient disturbances", IEEE Transaction on Instrumentation and Measurements, vol. 56(6): pp. 22322239,2007

[64] IEEE Std 1547-2003, IEEE standard for interconnecting distributed resources with electric power systemsAmendment 1, The Institute of Electrical and Electronics Engineers, 2014.
[65] Dugan, Roger C., Mark F. McGranaghan., and Wayne Beaty, H., "Electrical power systems quality." New York, NY: McGraw-Hill,| c19961996.

[66] Natesan., Chitra., Senthil Kumar Ajithan., Priyadharshini Palani., and Prabaakaran Kandhasamy., "Survey on microgrid: power quality improvement techniques", ISRN Renewable Energy 20142014.

[67] Chung, Il-Yop., Wenxin Liu., David A. Cartes., Emmanuel G. Collins., and Seung-Il Moon., "Control methods of inverter-interfaced distributed generators in a microgrid system", IEEE Transactions on Industry Applications, vol. 46(3) : pp. 1078-1088, 2010.

[68] Yu., Kai., Qian Ai., Shiyi Wang., Jianmo Ni., and Tianguang Lv., "Analysis and optimization of droop controller for microgrid system based on small-signal dynamic model", IEEE Transactions on Smart Grid, vol. 7(2) : pp. 695-705, 2016.

[69] Meng., Lexuan., Tomislav Dragicevic., Javier RoldánPérez., Juan C. Vasquez., and Josep M. Guerrero., "Modeling and sensitivity study of consensus algorithmbased distributed hierarchical control for $\mathrm{dc}$ microgrids", IEEE Transactions on Smart Grid, vol. 7(3) : pp. 1504-1515, 2016.

[70] Chen., Wu., Alex Q. Huang., Chushan Li., Gangyao Wang., and Wei Gu., "Analysis and comparison of medium voltage high power DC/DC converters for offshore wind energy systems", IEEE Transactions on Power Electronics, vol.28(4): pp.2014-2023, 2013.

[71] Hossain., Eklas., Ersan Kabalci., Ramazan Bayindir., and Ronald Perez., "Microgrid testbeds around the world: State of art", Energy Conversion and Management, vol. 86: pp. 132- 153, 2014.

[72] Golsorkhi., Mohammad S., and Dylan Dah-Chuan Lu., "A Decentralized Control Method for Islanded Microgrids Under Unbalanced Conditions", IEEE Transactions on Power Delivery, vol. 31(3): pp. 1112-1121, 2016.

[73] Mariam., Lubna., Malabika Basu., and Michael F. Conlon., "Microgrid: Architecture, policy and future trends", Renewable and Sustainable Energy Reviews, vol. 64 : pp. 477-489, 2016.

[74] Al-Saedi., Waleed., Stefan W. Lachowicz., Daryoush Habibi., and Octavian Bass. "Power flow control in gridconnected microgrid operation using Particle Swarm Optimization under variable load conditions", International Journal of Electrical Power \& Energy Systems, vol. 49: pp. 76-85, 2013.

[75] Al-Saedi., Waleed., Stefan W. Lachowicz., Daryoush Habibi., and Octavian Bass., "Voltage and frequency regulation based DG unit in an autonomous microgrid operation using Particle Swarm Optimization", International Journal of Electrical Power \& Energy Systems, vol. 53: pp. 742-751, 2013.

[76] Ray, R.N., Chatterjee, D., and Goswami, S.K., "Reduction of voltage harmonics using optimisation - based combined approach", IET Power Electronics, vol. 3(3): pp. 334-344, 2010.

[77] Hassan, M., and Abido, M., "Optimal power sharing of an inverter - based autonomous microgrid", In: Conference on Renewable Energies and Power Quality (ICREPQ'13), Spain, 20-22, 2013.

[78] Abdelaziz., Morad Mohamed Abdelmageed., Hany E. Farag., and Ehab F. El-Saadany., "Optimum reconfiguration of droop-controlled islanded microgrids", IEEE Transactions on Power Systems, vol. 31(3): pp. 2144-2153, 2016.

[79] Abedini., Mohammad., Mohammad H. Moradi., Hosseinian, S.M., Optimal clustering of MGs based on 
droop controller for improving reliability using a hybrid of harmony search and genetic algorithms", ISA transactions, vol. 61: pp.119-128, 2016.

[80] Chitra, N., Prabaakaran, K., Senthil Kumar, A., and Josiah Munda., "Ant colony optimization adopting control strategies for power quality enhancement in autonomous microgrid.", International Journal of Computer Applications, vol. 63(13), 2013.

[81] Asrari, A., Lotfifard, S., Payam, M.S., "Pareto dominance-based multiobjective optimization method for distribution network reconfiguration", IEEE Transactions on Smart Grid, vol. 7(3): pp. 1401-1410, 2016.

[82] Sontakke, S., Thorat, A., "Novel method for estimation of PQ indices in microgrids", In: Conference on Energy Efficient Technologies for Sustainability ICEETS' 13. Nagercoil, April 2013, pp.1159-1163, 2013.

[83] Fathima. A. H., Palanisamy, K., "Optimization in microgrids with hybrid energy systems-A review", Renewable and Sustainable Energy Reviews, vol. 31(45): pp. 431-446, 2015.

[84] Poonam Singhal., and Agarwal, Narendra Kumar S. K., "Advanced Adaptive Particle Swarm Optimization based SVC Controller for Power System Stability", I.J. Intelligent Systems and Applications, vol. 7(1):pp.101110, 2015.

[85] Nader M.A. Ibrahim., Hossam E. M. Attia., Hossam E.A. Talaat., and Ali H. Kasem Alaboudy., "Modified Particle Swarm Optimization Based Proportional-Derivative Power System Stabilizer", I.J. Intelligent Systems and Applications, vol. 7(3): pp.62-76, 2015.

[86] Indragandhi. V., Subramaniyaswamy V., and Logesh R., "Resources, configurations, and soft computing techniques for power management and control of PV/wind hybrid system", Renewable and Sustainable Energy Reviews, vol. 69: pp.129-143, 2017.

[87] Usman Bashir Tayaba., Mohd Azrik Bin Roslana., Leong Jenn Hwaia., and Muhammad Kashif., "A review of droop control techniques for microgrid", Renewable and Sustainable Energy Reviews, vol.76: pp.717-727, 2017.

\section{Authors' Profiles}

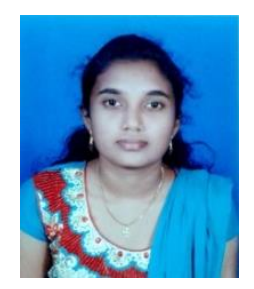

W. J. Praiselin received the B.E. degree in Electrical and Electronics Engineering from Udaya School of Engineering, Tamilnadu, India in 2013; M.E. degree in Power Systems Engineering from Francis Xavier Engineering College, Tamilnadu, India in 2015. She is currently a Ph.D in VIT University, Vellore, India. Her research interests include power system, power quality improvement in micro grids, control operations, FACTS devices and integration of renewable energy sources.

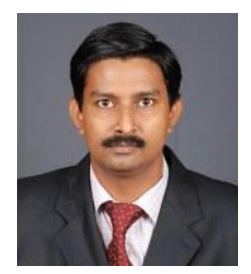

J. Belwin Edward was born in 1977. He received his B.E., Degree in electrical engineering from Manonmaniam Sundaranar University, Tamilnadu, India in 1999. M.E. degree in Power Systems from Annamalai University, Tamilnadu, India in 2002 and PhD from Anna University, Chennai in 2013. He has more than 14 years of experience in teaching and research. His major scientific interest is focused on Power system Optimization and protection, optimal location of FACTS and DG devices, Renewable Energy Systems.

How to cite this paper: W. J. Praiselin, J. Belwin Edward, "A Review on Impacts of Power Quality, Control and Optimization Strategies of Integration of Renewable Energy Based Microgrid Operation", International Journal of Intelligent Systems and Applications(IJISA), Vol.10, No.3, pp.67-81, 2018. DOI: 10.5815/ijisa.2018.03.08 